Western University Scholarship@Western

Electrical and Computer Engineering Publications Electrical and Computer Engineering Department

$12-2012$

\title{
Fuzzy-ExCOM Software Project Risk Assessment
}

\author{
Luiz Fernando Capretz \\ University of Western Ontario, lcapretz@uwo.ca \\ Ekananta Manalif \\ London Hydro, ekananta@gmail.com \\ Ali Bou Nassif \\ University of Western Ontario, abounas@uwo.ca \\ Danny Ho \\ NFA Estimation Inc., danny@nfa-estimation.com
}

Follow this and additional works at: https://ir.lib.uwo.ca/electricalpub

Part of the Other Computer Sciences Commons, and the Software Engineering Commons

\section{Citation of this paper:}

@inproceedings\{DBLP:conf/icmla/ManalifCNH12, author $=\{$ Ekananta Manalif and Luiz Fernando Capretz and Ali Bou Nassif and Danny Ho $\}$, title $=\{$ Fuzzy-ExCOM Software Project Risk Assessment $\}$, booktitle $=\{$ ICMLA (2) $\}$, year $=\{2012\}$, pages $=\{320-325\}$, ee $=\{\mathrm{http}: / / \mathrm{dx}$.doi.org/10.1109/ICMLA.2012.193 $\}$, crossref $=\{$ DBLP:conf $/$ icmla/2012-2 $\}$, bibsource $=\{$ DBLP, http: $/ / \mathrm{dblp} . u n i-$ trier.de $\}\} @$ proceedings $\{$ DBLP:conf/icmla/2012-2, title $=\{11$ th International Conference on Machine Learning and Applications, ICMLA, Boca Raton, FL, USA, December 12-15, 2012. Volume 2 $\}$, booktitle $=\{\operatorname{ICMLA}(2)\}$, publisher $=\{\operatorname{IEEE}\}$, year $=\{2012\}$, isbn $=\{978-1-4673-4651-1\}$, ee $=\{$ http: $/ /$ ieeexplore.ieee $. o r g / x p l /$ mostRecentIssue.jsp? punumber $=6403616\}$, bibsource $=\{$ DBLP, http://dblp.uni-trier.de\} $\}$ 


\section{Fuzzy-ExCOM Software Project Risk Assessment}

\author{
Ekananta, Luiz Fernando Capretz, Ali Bou Nassif \\ University of Western Ontario \\ Department of Electrical and Computer Engineering \\ London, Ontario N6A 5B9, Canada \\ \{exx, lcapretz\}@uwo.ca
}

\author{
Danny Ho \\ NFA Estimation Inc. \\ Richmond Hill, Ontario, L4C 0A2, Canada \\ danny@nfa-estimation.com
}

\begin{abstract}
A software development project can be considered to be risky project due to the uncertainty of the information (customer requirements), the complexity of the process, and the intangible nature of the product. Under these conditions, risk management in software development projects is mandatory, but often it is difficult and expensive to implement.
\end{abstract}

Expert COCOMO is an efficient approach to software project risk management, which leverages existing knowledge and expertise from previous effort estimation activities to assess the risk in a new software project. However, the original method has a limitation because it cannot effectively deal with imprecise and uncertain inputs in the form of linguistic terms such as: Very Low (VL), Low (L), Nominal (N), High (H), Very High (VH) and Extra High (XH).

This paper introduces the fuzzy-ExCOM methodology that combines the advantages of a fuzzy technique with Expert COCOMO methodology for risk assessment in a software project. A validation of this approach with project data shows that fuzzy-ExCOM provides better risk assessment results with a higher level of sensitivity with respect to risk identification compared to the original Expert COCOMO methodology.

Key words: software project, fuzzy technique, risk assessment.

\section{INTRODUCTION}

As the most uncertain and complex project when compared to other types of projects, a successful software development project is highly dependent on the initial Project Planning Phase, which involves several activities to determine the project's scope, scheduling, cost, available resources, and risk [1].

The numerous activities in the software project planning phase can be grouped into two major activities, namely effort estimation and risk management [2]. Software effort estimation calculates the effort that is required in a software development project based on several cost factors while risk management activities include identifying, addressing, and eliminating software project risks before undesirable outcomes occur.

As compared to an effort estimation activity, risk management, especially risk assessment, in software project planning is rarely practised and is often difficult to implement because of the scarcity of experts in risk management, the unique project characteristics, the lack of sufficient time to do a thorough analysis, and perceived as being too effort intensive and costly [3][4].

Expert COCOMO is one efficient approach to software project risk management, which leverages the existing knowledge and expertise taken from previous effort estimation activities to assess the level of risk in a new software development project.

This research combines fuzzy logic, which has the capability to deal with situation ambiguity and linguistic variables, to improve the sensitivity of software project risk assessments using Expert COCOMO. The proposed methodology provides a better result that can be used as a decision support system for an individual project manager or a top management team in making project comparisons based on their risks or to prepare better project risk mitigation approaches.

The paper is organized as follows: Section II describes the Software Risk Management. Section III describes the Expert COCOMO methodology, Section IV deals with FuzzyExCOM, and Section V describes the model validation. The Conclusion and suggestions for future work are presented in Section VI.

\section{SOFTWARE RISK MANAGEMENT}

Risk always involves uncertainty and the potential for loss [5]. Risk in a software development project is also known as "software risk" and is defined as "a measure of likelihood of an unsatisfactory outcome affecting the software project, process, or product" [6].

Risk Management can be described as all the necessary actions that should be taken to manage a risk. The two main phases of risk-management are Risk-Assessment and RiskControl. Risk-Assessment is a discovery process of identifying the sources of risks, analyzing or evaluating the potential risk effects, and prioritizing the risks. Risk-Control is the process of developing software risk resolution plans, monitoring the risk status, implementing a risk resolution plan, and resolving the risk issues by correcting potential deviations from the plan. The scope of software risk management activities is shown in Figure 1. 


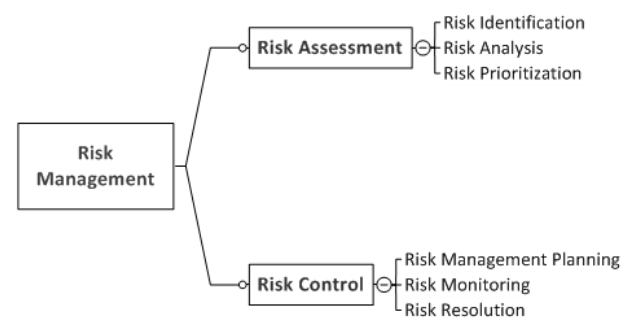

Figure 1. Risk Management Activities [7]

Risk assessment which is the main activity in a project planning phase, plays a vital role in determining the success of a software development project [8]. However, the success of a risk assessment activity with respect to the popular risk management methods [5][9][10][11][12] is highly dependent on human judgment and experience

\section{EXPERT COCOMO}

Expert COCOMO is an extension of COCOMO-II that is used to aid in project planning by identifying, categorizing, and prioritizing project risks. This method was introduced by Ray Madachy [3] with the primarily aim to detect and analyze the input anomaly for project effort estimation. Expert COCOMO utilizes the information taken from effort estimation activities to establish a risk assessment of a particular software project.

The risk taxonomy in Expert COCOMO establishes that Software Risk consists of several risks that are related to COCOMO cost factors, such as: Schedule Risk, Product Risk, Platform Risk, Personnel Risk, Process Risk, and Reuse Risk. The software risk taxonomy in Expert COCOMO is described in Figure 2.All risks in Expert COCOMO are defined as the result of a combination of several cost factors. Risk rules determine the level of every risk by mapping 2 cost factors (attributes) according to a risk level assignment matrix as shown in Figure 3.



Figure 2. Expert COCOMO Risk Taxonomy [3]

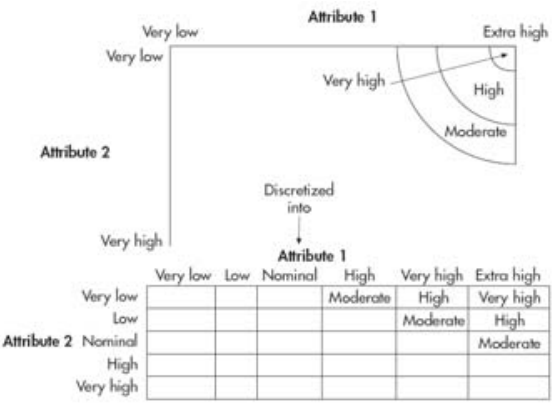

Figure 3. Risk Level Assignment Matrix [3]

Overall Software Project Risk quantifies the level of risk as it relates to the combination of cost factors in a software project as described in the equation formula (1), where the effort multiplier product $=$ (driver $\# 1$ effort multiplier) $\mathrm{x}$ (driver \#2 effort multiplier) x . . . x (driver \#n effort multiplier) [3].

$$
\text { Project risk }=\sum_{j=1}^{\text {No. antgyries }} \sum_{i=1}^{\text {No.cantgayrishts }} \text { risklevel }_{i j} \times \text { effort multiplier product }{ }_{i j}
$$

The recent Expert COCOMO application was developed using a C program and an HTML interface and is posted at the USC website [13]

The main advantage of Expert COCOMO is its capability to use the existing knowledge from a previous effort estimation activity to perform an early stage project risk assessment. Expert COCOMO eliminates the requirement for risk management expertise and integrates the risk assessment with effort estimation. However, this method has a limitation in dealing with inputs from cost factors in the form of linguistic terms such as: Very Low (VL), Low (L), Nominal (N), High $(\mathrm{H})$, Very High $(\mathrm{VH})$ and Extra High $(\mathrm{XH})$ which affected the accuracy and sensitivity in identifying and determining the project risks

\section{FUZZY-EXCOM}

Fuzzy logic is a methodology introduced by Prof. Lofti Zadeh, which aims to serve as a tool for dealing with uncertainty, imprecision, and complex problems that are difficult to solve quantitatively [14]. A fuzzy system consists of three main components [15][16]: the fuzzification process, inferences from fuzzy rules, and the defuzzification process.

Fuzzy-ExCOM (Fuzzy Expert COCOMO) is the software risk assessment methodology based on fuzzy-logic and Expert COCOMO. Fuzzy logic improves the sensitivity of risk identification with Expert COCOMO and is applied to the cost factor parameters as the input for Expert COCOMO that usually describes the qualitative measurements such as very low, low, nominal, high, and very high. Figure 4 provides an overview of fuzzy-ExCOM. 


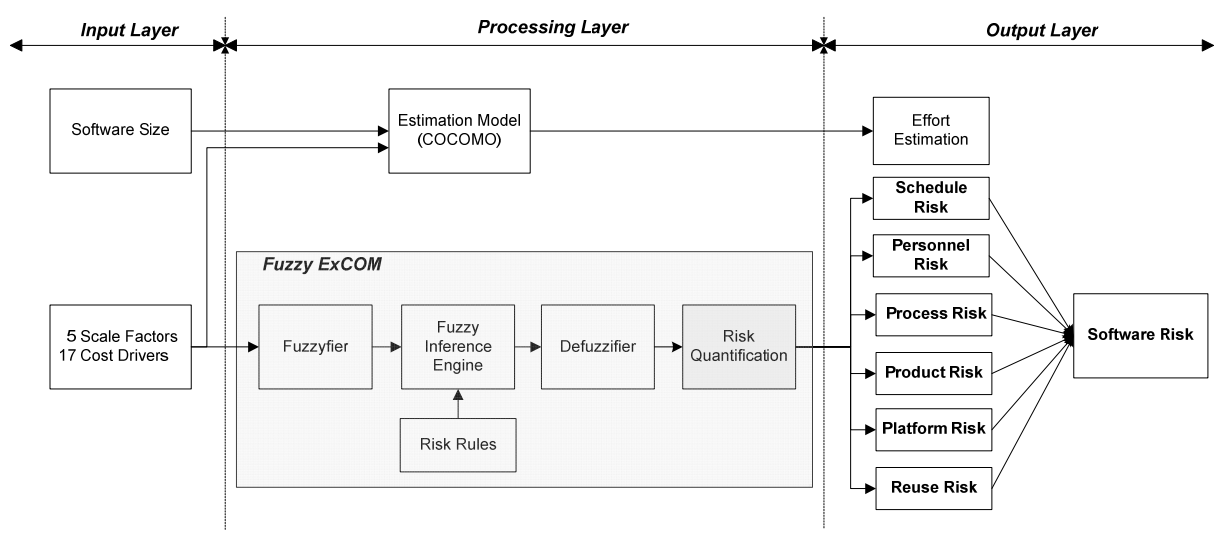

Figure 4. Fuzzy-ExCOM (fuzzy Expert COCOMO)

The fuzzification process is the process of transforming crisp input to the fuzzy value sets based on membership function (MF) and allows the input to the system to be expressed in linguistic terms. In the fuzzy-ExCOM model, the fuzzifier converts the qualitative input of cost factors to the fuzzy values using the Gaussian membership function. Figure 5 illustrates the membership function of the CPLX cost factor.

The inference process involves a fuzzy inference engine, which performs the mapping steps between the input from the fuzzification process and the output based on expert knowledge or fuzzy rules. The Fuzzy Inference Engine in fuzzy-ExCOM determines the level of every risk based on the input from 2 cost factors and the risk rules that they represent according to a risk level assignment matrix. Figure 6 shows the risk level matrix for the SCED and CPLX cost factors. Based on this risk-rule, the development project for a product with a veryhigh complexity (CPLX) level has a very-high scheduling and product risk if it is executed under a very-low project schedule (SCED).

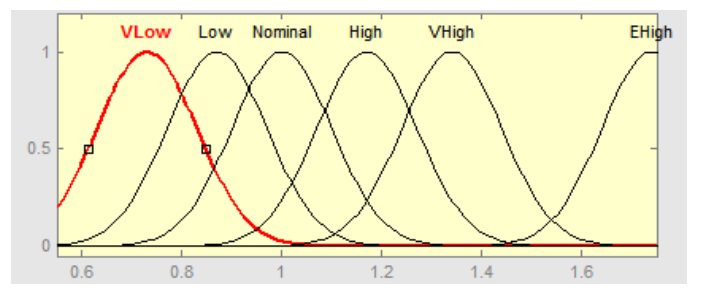

Figure 5. Fuzzy-ExCOM (fuzzy Expert COCOMO)

\begin{tabular}{|c|c|c|c|c|c|}
\hline & & & SCED & & \\
\hline & Very Low & Low & Nominal & High & Very High \\
\hline \multicolumn{6}{|l|}{ Very Low } \\
\hline \multicolumn{6}{|c|}{ Very Low } \\
\hline \multirow{3}{*}{$\begin{array}{l}\text { Nominal } \\
\text { High } \\
\text { Very High }\end{array}$} & Low & Very Low & & & \\
\hline & Moderate & Low & Very Low & & \\
\hline & High & Moderate & Low & Very Low & \\
\hline Extra High & VeryHigh & High & Moderate & Low & VeryLow \\
\hline
\end{tabular}

Figure 6. Fuzzy-ExCOM (fuzzy Expert COCOMO)
There are 31 risk rules inherent in fuzzy-ExCOM based on rules implemented in an Expert-COCOMO application. A sample of a cplx_sced rule implementation is shown in Figure 7.



Figure 7. CPLX_SCED rule

The last process in the fuzzy system is the defuzzification process, which produces and translates a fuzzy output to a quantifiable result. The defuzzifier in the fuzzy-ExCOM model translates every fuzzy risk level from an inference process to a quantifiable value that will be used to calculate the project risks based on a formula (1).

\section{Model VALidation}

To understand the effectiveness of a fuzzy system in improving risk assessment in a software project using Expert COCOMO, the proposed model is tested with 3 data sets. The first data set is COCOMO NASA93 public data provided by PROMISE [17], which consist of 93 project data points. The other data sets are the COCOMO data set from the Turkish Software Industry (12 project data points) [18] and the Industry data set (6 project data points) [19]. The overall steps in this process are: data preparation, risk assessment using Expert COCOMO, risk assessment using fuzzy-ExCOM, correlation calculation, and data analysis. The overall process of this activity is shown in Figure 8. 


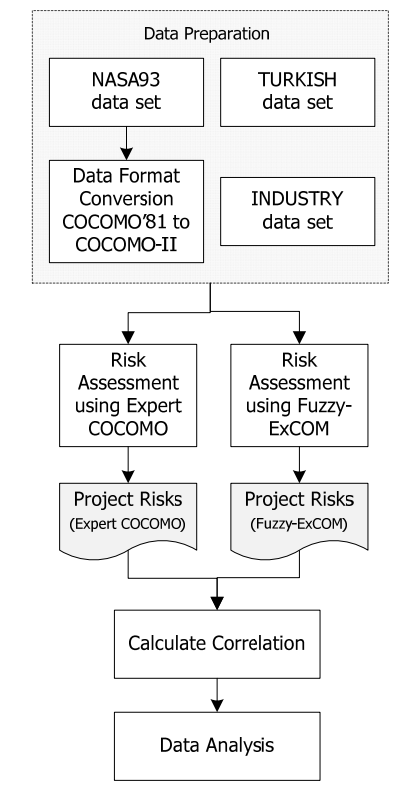

Figure 8. Fuzzy-ExCOM Model Validation

\section{A. Data Preparation}

The Expert COCOMO requires a cost factor as the input for the risk assessment activity in the COCOMO-II format. The data conversion is required for the NASA93 data set because the NASA93 project data points are in the COCOMO'81 data format, which is slightly different from the COCOMO-II format [19]. The data conversion is not required for the TURKISH data set and the INDUSTRY data set since both data sets are already in the COCOMO-II format.

\section{B. Risk Assessment using Expert COCOMO}

The Expert COCOMO implementation in a software project risk assessment is based on the application that is posted on the USC site [14]. The outputs of this application are estimated effort, project risk, schedule risk, product risk, platform risk, personnel risk, process risk, and reuse risk. Table IV shows the partial results of Expert COCOMO for the NASA93 data set and Table VI shows the partial results for the Expert COCOMO for the TURKISH and INDUSTRY data sets

\section{Risk Assessment using fuzzy-ExCOM}

Fuzzy-ExCOM is an improved version of Expert COCOMO that implements the fuzzy system in the original methods. For validation purposes, MATLAB R2009b is used as the main tool in the implementation of the fuzzy-ExCOM risk assessment model. Table $\mathrm{V}$ shows the partial results from fuzzy-ExCOM for the NASA93 data set and Table VII shows the partial results of fuzzy-ExCOM for the TURKISH and INDUSTRY data sets.

\section{Calculate Correlation}

The Correlation Coefficient is calculated to explain the degree of correlation between project risks and other project parameters. It also provides the information about the sensitivity of project risks to the variations in these parameters. This paper calculates the correlation coefficient between the project risk and the software size and the actual project effort. Software size in a software development project is having a proportional relationship with project risk; the larger software size means a higher project risk [20]. Project risks also have a relationship with project effort because the problems in project execution that come from the potential project risks will be carried over to project effort [3].

Table I shows the correlation between project risk versus software size and actual effort based on Expert COCOMO and the fuzzy-ExCOM approach for the NASA93 data set.

\begin{tabular}{l|c|c}
\hline $\begin{array}{c}\text { corr } \\
\text { (93 NASA data points) }\end{array}$ & $\begin{array}{c}\text { Size } \\
\text { (KSLOC) }\end{array}$ & $\begin{array}{c}\text { ACT Effort } \\
\text { (person-mo) }\end{array}$ \\
\hline Expert COM Risk & 0.05 & 0.02 \\
\hline fuzzy-ExCOM Risk & 0.25 & 0.31 \\
\hline
\end{tabular}

TABLE I. RISK CORRELATION WITH SIZE AND ACTUAL EFFORT (NASA93 DATA SET)

Table II shows the correlation results for the TURKISH data set and the correlation results for the INDUSTRY data set is shown in Table III. The correlation chart diagram for risk against software size for NASA93 data set is shown in Figure 9.

\begin{tabular}{l|c|c}
\hline $\begin{array}{c}\text { corr } \\
\text { (12 TURKISH data points) }\end{array}$ & $\begin{array}{c}\text { Size } \\
\text { (KSLOC) }\end{array}$ & $\begin{array}{c}\text { ACT Effort } \\
\text { (person-mo) }\end{array}$ \\
\hline Expert COM Risk & 0.00 & -0.04 \\
\hline fuzzy-ExCOM Risk & 0.63 & 0.53 \\
\hline
\end{tabular}

TABLE II. RISK CORRELATION WITH SIZE AND ACTUAL EFFORT (TURKISH DATA SET)

\begin{tabular}{l|c|c}
\hline $\begin{array}{c}\text { Corr } \\
\text { (6 INDUSTRY data points) }\end{array}$ & $\begin{array}{c}\text { Size } \\
\text { (KSLOC) }\end{array}$ & $\begin{array}{c}\text { ACT Effort } \\
\text { (person-mo) }\end{array}$ \\
\hline Expert COM Risk & 0.00 & 0.00 \\
\hline fuzzy-ExCOM Risk & -0.42 & -0.37 \\
\hline
\end{tabular}

TABLE III. RISK CORRELATION WITH SIZE AND ACTUAL EFFORT (INDUSTRY DATA SET)

\section{E. Data Analysis}

Based on the Expert COCOMO calculation shown in Table IV and Table VI, most of the projects were considered to be low risk projects with only 1 project being considered as a moderate risk project. On the other hand, the risk calculation result using fuzzy-ExCOM as shown in Table V and Table VII, categorizes the projects as low, moderate, and high risk projects.

For the NASA93 data set, there were 21 projects, which were considered to be low risk projects, 55 projects, which were considered to be moderate risk projects, and 17 projects, which were considered to be high risk projects. For the 
TURKISH data set, there were 10 projects, which were considered to be low risk projects, and 2 projects, which were considered to be moderate risk projects. For the INDUSTRY data set, there were 4 projects, which were considered to be low risk projects, and 2 projects, which were considered to be moderate risk projects.
Table I, Table II, and Table III show that fuzzy-ExCOM risk assessment results are producing a higher correlation with software size and actual effort for all of the data sets. Thus, it can be said that fuzzy-ExCOM provides a better and more sensitive risk assessment result compare to the original method.

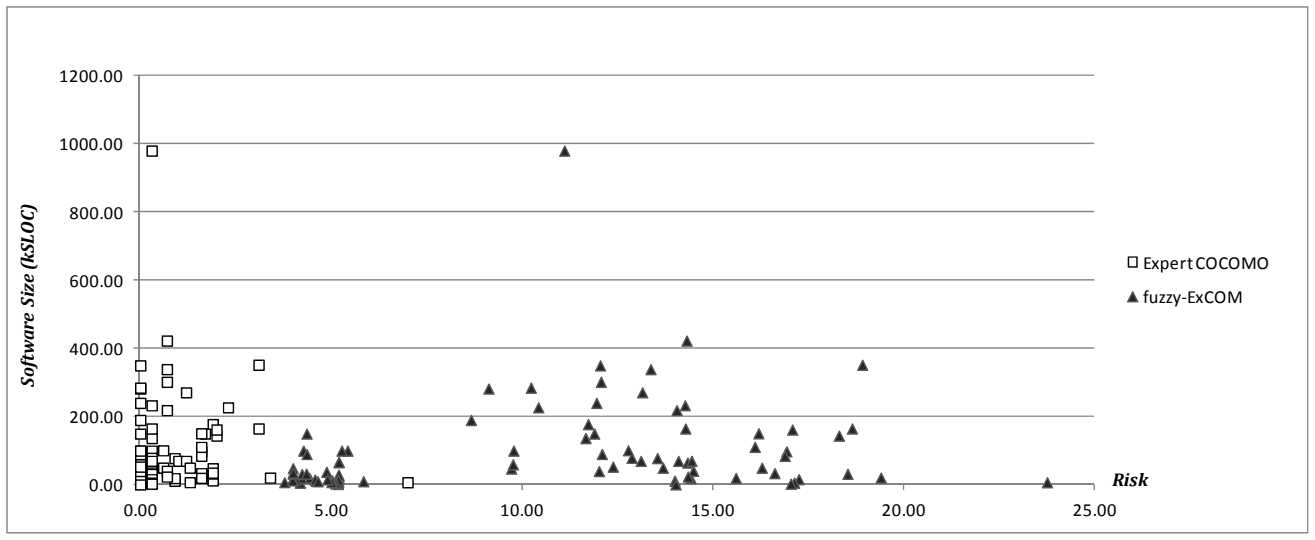

Figure 9. Project Risk Correlation with Software Size (NASA93 data set)

\section{CONCLUSIONS AND FUTURE WORKS}

A software development project can be considered to be one of the riskier projects in the modern era. This high risk condition is driven by the uncertainty of customer requirements, the process (people, methodology, tools), and the intangible nature of the product. These factors could have a significant impact on the project schedule, the quality of the product, and the related costs.

In such a situation, risk management - especially risk assessment - becomes a mandatory activity for software projects, but is often difficult and expensive to implement. Fuzzy-ExCOM is a risk assessment methodology for a software project that combines the advantages of a fuzzy system with Expert COCOMO. This paper shows that fuzzyExCOM provides an efficient risk assessment with a higher sensitivity in risk identification, analysis, and prioritization as compared to the original Expert COCOMO methodology.

Future investigations in this area, which are designed to improve the accuracy and sensitivity of this methodology, can be focused on increasing the number of inference rules, improving risk category, improving the risk quantification rules, and considering the utilization of other methods such as neuro-fuzzy logic in risk assessment

\section{REFERENCES}

[1] PMI (Project Management Institute), "A guide to the Project Management Body of Knowledge (PMBOOK Guide)," $4^{\text {th }} \mathrm{Ed}, 2008$.

[2] R.S. Pressman, "Software engineering - Practitioner's approach," $6^{\text {th }}$ Ed, Mc Graw Hill, NY, 2005, pp. 644

[3] R. Madachy, "Heuristic risk assessment using cost factors," IEEE Software May/June, Vol.14 No.3, 1997, pp. 51-59
[4] E.E. Odzaly, D. Greer, P. Sage, "Software risk management barriers: en Empirical Study,” $3^{\text {rd }}$ International Symposium on Empirical Software Engineering and Measurement, 2009, pp. 418-421

[5] E.M. Hall, "Managing risk: Methods for software systems development," Addison Wesley Longman, Inc., 1998.

[6] R.S. Pressman, "Software engineering - Practitioner's approach," $6^{\text {th }}$ Ed, Mc Graw Hill, NY, 2005, pp. 696

[7] B.W. Boehm, "Software risk management: Principles and practice," IEEE Software, Vol.8, Issue.1, Jan 1991, pp. 32-41.

[8] K. Heldman, W. Heldman, “CompTIA Project+: Study guide,” Wiley Publishing Inc., 2010, pp. 34

[9] C. Jones, "Assessment and control of software risks," Yourdon Press Prentice Hall, 1994.

[10] D.W. Karolak, "Software engineering risk management," IEEE Computer Society Press, 1996.

[11] R.N. Charette, "Software engineering risk analysis and management," McGraw Hill, 1989.

[12] M.J. Carr, S.L. Konda, F.C. Ulrich, C.F. Walker, "Taxonomy-based risk identification,” SEI Technical Report SEI-93-TR-006, Pittsburgh PA, 1993

[13] http://sunset.usc.edu/research/COCOMOII/expert_cocomo/expert_coco mo2000.html, access on Nov 2011.

[14] L.A. Zadeh, "Fuzzy sets, information and control," Volume 8, Elsevier, 1965, pp. 338-353

[15] Y.C. Shin, C. Xu, "Intelligent systems: Modeling, optimization, and control,” Taylor \& Francis Group, LLC, 2009, pp. 22-26

[16] H. Xishi, D. Ho, L.F. Capretz, "Improving COCOMO model using a neuro-fuzzy approach,” Applied Soft Computing Vol.7, 2007, pp. 2940.

[17] NASA93 COCOMO data set - http://promise.site.uottawa.ca/ SERepository/datasets-page.html

[18] Turkish Software Industry data set - http://promisedata.org/ repository/data/cocomo_sdr/cocomo_sdr.arff

[19] W.L. Du,,"A Neuro-fuzzy Model with SEER-SEM for software effort estimation", MESc Thesis, University of Western Ontario, Canada, 2009.

[20] C. Jones, "Early sizing and early risk analysis of software projects", Capers Jones \& Associates LLC, 2012 


\begin{tabular}{ccccccccccc}
\hline $\begin{array}{c}\text { Project } \\
\text { ID }\end{array}$ & $\begin{array}{c}\text { Size } \\
\text { (KsLC) }\end{array}$ & $\begin{array}{c}\text { Actual Effort } \\
\text { (person-mo) }\end{array}$ & $\begin{array}{c}\text { Risk } \\
\text { Level }\end{array}$ & $\begin{array}{c}\text { Project } \\
\text { Risk }\end{array}$ & $\begin{array}{c}\text { Schedule } \\
\text { Risk }\end{array}$ & $\begin{array}{c}\text { Product } \\
\text { Risk }\end{array}$ & $\begin{array}{c}\text { Platform } \\
\text { Risk }\end{array}$ & $\begin{array}{c}\text { Personnel } \\
\text { Risk }\end{array}$ & $\begin{array}{c}\text { Process } \\
\text { Risk }\end{array}$ & $\begin{array}{c}\text { Reuse } \\
\text { Risk }\end{array}$ \\
\hline \hline 76 & 162.00 & 756.00 & Low & 2.00 & 2.80 & 3.00 & 0.00 & 0.00 & 8.30 & 0.00 \\
\hline 77 & 352.00 & 1200.00 & Low & 3.10 & 2.80 & 6.40 & 0.00 & 0.00 & 11.80 & 0.00 \\
78 & 165.00 & 97.00 & Low & 3.10 & 2.80 & 6.30 & 0.00 & 0.00 & 11.60 & 0.00 \\
79 & 60.00 & 409.00 & Low & 0.00 & 0.00 & 0.00 & 0.00 & 0.00 & 0.00 & 0.00 \\
80 & 100.00 & 703.00 & Low & 0.00 & 0.00 & 0.00 & 0.00 & 0.00 & 0.00 & 0.00 \\
81 & 32.00 & 1350.00 & Low & 0.30 & 0.00 & 1.40 & 0.00 & 0.00 & 0.00 & 0.00 \\
82 & 53.00 & 480.00 & Low & 0.00 & 0.00 & 0.00 & 0.00 & 0.00 & 0.00 & 0.00 \\
83 & 41.00 & 599.00 & Low & 0.70 & 2.70 & 0.00 & 0.00 & 0.90 & 0.00 & 0.00 \\
84 & 24.00 & 430.00 & Low & 0.70 & 2.70 & 0.00 & 0.00 & 0.90 & 0.00 & 0.00 \\
85 & 165.00 & 4178.20 & Low & 0.30 & 0.00 & 1.50 & 0.00 & 0.00 & 0.00 & 0.00 \\
86 & 65.00 & 1772.50 & Low & 0.30 & 0.00 & 1.50 & 0.00 & 0.00 & 0.00 & 0.00 \\
87 & 70.00 & 1645.90 & Low & 0.30 & 0.00 & 1.50 & 0.00 & 0.00 & 0.00 & 0.00 \\
88 & 50.00 & 1924.50 & Low & 1.30 & 0.00 & 3.60 & 0.00 & 0.00 & 3.90 & 0.00 \\
89 & 7.25 & 648.00 & Moderate & $\mathbf{7 . 0 0}$ & 0.00 & 11.70 & 7.20 & 8.50 & 2.70 & 0.00 \\
\hline 90 & 233.00 & 8211.00 & Low & 0.30 & 0.00 & 1.50 & 0.00 & 0.00 & 0.00 & 0.00 \\
91 & 16.30 & 480.00 & Low & 0.30 & 0.00 & 1.40 & 0.00 & 0.00 & 0.00 & 0.00 \\
\hline 92 & 6.20 & 12.00 & Low & 0.30 & 0.00 & 1.40 & 0.00 & 0.00 & 0.00 & 0.00 \\
93 & 3.00 & 38.00 & Low & 0.30 & 0.00 & 1.30 & 0.00 & 0.00 & 0.00 & 0.00 \\
\hline
\end{tabular}

TABLE IV. Project Risk AsSesSment using EXPERT COCOMO (NASA93 PARTIAL DATA SET)

\begin{tabular}{ccccccccccc}
\hline $\begin{array}{c}\text { Project } \\
\text { ID. }\end{array}$ & $\begin{array}{c}\text { Size } \\
\text { (KSLOC) }\end{array}$ & $\begin{array}{c}\text { Actual Effort } \\
\text { (person-mo) }\end{array}$ & $\begin{array}{c}\text { Risk } \\
\text { Category }\end{array}$ & $\begin{array}{c}\text { Project } \\
\text { Risk }\end{array}$ & $\begin{array}{c}\text { Schedule } \\
\text { Risk }\end{array}$ & $\begin{array}{c}\text { Personnel } \\
\text { Risk }\end{array}$ & $\begin{array}{c}\text { Process } \\
\text { Risk }\end{array}$ & $\begin{array}{c}\text { Product } \\
\text { Risk }\end{array}$ & $\begin{array}{c}\text { Platform } \\
\text { Risk }\end{array}$ & $\begin{array}{c}\text { Reuse } \\
\text { Risk }\end{array}$ \\
\hline \hline $\mathbf{7 6}$ & $\mathbf{1 6 2 . 0 0}$ & $\mathbf{7 5 6 . 0 0}$ & High & 17.07 & 26.73 & 20.48 & 47.74 & 14.59 & 15.48 & 2.32 \\
$\mathbf{7 7}$ & $\mathbf{3 5 2 . 0 0}$ & $\mathbf{1 2 0 0 . 0 0}$ & High & 18.90 & 27.40 & 21.10 & 54.03 & 20.67 & 15.48 & 2.32 \\
$\mathbf{7 8}$ & $\mathbf{1 6 5 . 0 0}$ & $\mathbf{9 7 . 0 0}$ & High & 18.63 & 27.12 & 20.94 & 52.74 & 20.40 & 15.48 & 2.32 \\
$\mathbf{7 9}$ & $\mathbf{6 0 . 0 0}$ & $\mathbf{4 0 9 . 0 0}$ & Moderate & 9.76 & 14.04 & 19.74 & 13.20 & 13.20 & 10.31 & 2.32 \\
$\mathbf{8 0}$ & $\mathbf{1 0 0 . 0 0}$ & $\mathbf{7 0 3 . 0 0}$ & Moderate & 9.77 & 14.05 & 19.75 & 13.26 & 13.22 & 10.31 & 2.32 \\
$\mathbf{8 1}$ & $\mathbf{3 2 . 0 0}$ & $\mathbf{1 3 5 0 . 0 0}$ & High & 18.52 & 21.33 & 41.55 & 29.18 & 20.15 & 19.23 & 6.71 \\
$\mathbf{8 2}$ & $\mathbf{5 3 . 0 0}$ & $\mathbf{4 8 0 . 0 0}$ & Moderate & 12.37 & 19.05 & 19.13 & 23.67 & 13.08 & 15.07 & 2.32 \\
$\mathbf{8 3}$ & $\mathbf{4 1 . 0 0}$ & $\mathbf{5 9 9 . 0 0}$ & Moderate & 14.48 & 22.79 & 30.87 & 21.86 & 12.11 & 10.34 & 10.03 \\
$\mathbf{8 4}$ & $\mathbf{2 4 . 0 0}$ & $\mathbf{4 3 0 . 0 0}$ & Moderate & 14.34 & 22.65 & 30.75 & 21.28 & 11.90 & 10.34 & 10.03 \\
$\mathbf{8 5}$ & $\mathbf{1 6 5 . 0 0}$ & $\mathbf{4 1 7 8 . 2 0}$ & Moderate & 14.27 & 18.13 & 22.68 & 28.15 & 20.33 & 14.85 & 2.32 \\
$\mathbf{8 6}$ & $\mathbf{6 5 . 0 0}$ & $\mathbf{1 7 7 2 . 5 0}$ & Moderate & 14.32 & 18.17 & 22.71 & 28.38 & 20.43 & 14.85 & 2.32 \\
$\mathbf{8 7}$ & $\mathbf{7 0 . 0 0}$ & $\mathbf{1 6 4 5 . 9 0}$ & Moderate & 14.43 & 18.25 & 22.76 & 28.86 & 20.61 & 14.85 & 2.32 \\
$\mathbf{8 8}$ & $\mathbf{5 0 . 0 0}$ & $\mathbf{1 9 2 4 . 5 0}$ & High & 16.27 & 18.69 & 26.85 & 30.99 & 27.68 & 14.85 & 2.32 \\
$\mathbf{8 9}$ & $\mathbf{7 . 2 5}$ & $\mathbf{6 4 8 . 0 0}$ & High & 23.74 & 25.93 & 54.30 & 38.33 & 29.78 & 20.23 & 8.52 \\
$\mathbf{9 0}$ & $\mathbf{2 3 3 . 0 0}$ & $\mathbf{8 2 1 1 . 0 0}$ & Moderate & 14.26 & 18.12 & 22.67 & 28.09 & 20.31 & 14.85 & 2.32 \\
$\mathbf{9 1}$ & $\mathbf{1 6 . 3 0}$ & $\mathbf{4 8 0 . 0 0}$ & High & 17.24 & 21.50 & 36.81 & 28.75 & 20.04 & 14.81 & 6.71 \\
$\mathbf{9 2}$ & $\mathbf{6 . 2 0}$ & $\mathbf{1 2 . 0 0}$ & High & 17.12 & 21.41 & 36.67 & 28.21 & 19.91 & 14.81 & 6.71 \\
$\mathbf{9 3}$ & $\mathbf{3} .00$ & $\mathbf{3 8 . 0 0}$ & High & 17.03 & 21.34 & 36.57 & 27.82 & 19.81 & 14.81 & 6.71 \\
\hline & & & & & & & & & & \\
\hline
\end{tabular}

TABLE V. PRoject Risk AsSessment using FuzZy ExCOM (NASA93 PARTIAL DATA SET)

\begin{tabular}{|c|c|c|c|c|c|c|c|c|c|c|}
\hline $\begin{array}{l}\text { Project } \\
\text { ID. }\end{array}$ & $\begin{array}{c}\text { Size } \\
\text { (KSLOC) }\end{array}$ & $\begin{array}{c}\text { Actual } \\
\text { Effort } \\
\text { (pers-mo) }\end{array}$ & $\begin{array}{l}\text { Risk } \\
\text { Level }\end{array}$ & $\begin{array}{l}\text { Project } \\
\text { Risk }\end{array}$ & $\begin{array}{l}\text { Schedule } \\
\text { Risk }\end{array}$ & $\begin{array}{l}\text { Personnel } \\
\text { Risk }\end{array}$ & $\begin{array}{l}\text { Process } \\
\text { Risk }\end{array}$ & $\begin{array}{c}\begin{array}{c}\text { Product } \\
\text { Risk }\end{array} \\
\text {. }\end{array}$ & $\begin{array}{l}\text { Platform } \\
\text { Risk }\end{array}$ & $\begin{array}{c}\text { Reuse } \\
\text { Risk }\end{array}$ \\
\hline (1011 & $\begin{array}{l}196.60 \\
\end{array}$ & $\begin{array}{l}638.00 \\
\end{array}$ & Low & 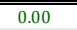 & $\overline{\overline{c 0.00}}$ & $\overline{\overline{c 0.00}}$ & 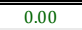 & $\overline{\overline{c 0.00}}$ & 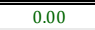 & $\overline{c 1.17}$ \\
\hline 102 & 51.80 & 185.00 & Low & 0.00 & 0.00 & 0.00 & 0.00 & 0.00 & 0.00 & 0.83 \\
\hline 103 & 64.10 & 332.00 & Low & 0.00 & 0.00 & 0.00 & 0.00 & 0.00 & 0.00 & 1.50 \\
\hline 104 & 131.00 & 619.90 & Low & 0.00 & 1.40 & 0.00 & 0.00 & 0.00 & 0.00 & 2.03 \\
\hline 105 & 13.30 & 64.80 & Low & 0.00 & 2.80 & 0.00 & 0.0 & 0.00 & 0.00 & 1.50 \\
\hline I06 & 19.90 & 76.60 & Low & 0.00 & 0.00 & 0.00 & 0.00 & 0.00 & 0.00 & 2.44 \\
\hline Т01 & 3.00 & 1.20 & Low & 0.30 & 0.00 & 120 & 0.00 & 0.00 & 0.00 & 0.00 \\
\hline Т02 & 2.00 & 2.00 & Low & 0.60 & 0.00 & 2.70 & 0.00 & 0.00 & 0.00 & 0.00 \\
\hline Т03 & 4.25 & 4.50 & Low & 0.60 & 0.00 & 2.70 & 0.00 & 0.00 & 0.00 & 0.00 \\
\hline T04 & 10.00 & 3.00 & Low & 0.00 & 0.00 & 0.00 & 0.00 & 0.00 & 0.00 & 0.00 \\
\hline T05 & 15.00 & 4.00 & Low & 0.30 & 0.00 & 1.20 & 0.00 & 0.00 & 0.00 & 0.00 \\
\hline T06 & 40.53 & 22.00 & Low & 0.70 & 2.90 & 0.00 & 0.00 & 0.00 & 3.00 & 0.00 \\
\hline T07 & 4.05 & 2.00 & Low & 0.70 & 2.90 & 0.00 & 0.00 & 0.00 & 3.00 & 0.00 \\
\hline Т08 & 31.85 & 5.00 & Low & 1.60 & 0.00 & 0.00 & 6.30 & 2.10 & 0.00 & 0.00 \\
\hline Т09 & 114.28 & 18.00 & Low & 0.00 & 0.00 & 0.00 & 0.00 & 0.00 & 0.00 & 0.00 \\
\hline T10 & 23.11 & 4.00 & Low & 3.50 & 6.22 & 1.80 & 9.50 & 3.10 & 0.00 & 0.00 \\
\hline $\mathrm{T} 11$ & 1.37 & 1.00 & Low & 0.00 & 0.00 & 0.00 & 0.00 & 0.00 & 0.00 & 0.00 \\
\hline T12 & 1.61 & 2.10 & Low & 0.00 & 0.00 & 0.00 & 0.00 & 0.00 & 0.00 & 0.00 \\
\hline
\end{tabular}

TABLE VI. PROJECT RISK ASSESSMENT USING EXPERT COCOMO (TURKISH- INDUSTRY DATA SET)

\begin{tabular}{|c|c|c|c|c|c|c|c|c|c|c|}
\hline $\begin{array}{l}\text { Project } \\
\text { ID. }\end{array}$ & $\begin{array}{c}\text { Size } \\
\text { (KSLOC) }\end{array}$ & $\begin{array}{c}\text { Actual } \\
\text { Effort } \\
\text { (pers-mo) }\end{array}$ & $\begin{array}{l}\text { Risk } \\
\text { Level }\end{array}$ & $\begin{array}{c}\text { Project } \\
\text { Risk }\end{array}$ & $\begin{array}{l}\text { Schedule } \\
\text { Risk }\end{array}$ & $\begin{array}{l}\text { Personnel } \\
\quad \text { Risk }\end{array}$ & $\begin{array}{c}\text { Process } \\
\text { Risk }\end{array}$ & $\begin{array}{c}\text { Product } \\
\text { Risk }\end{array}$ & $\begin{array}{l}\text { Platform } \\
\text { Risk }\end{array}$ & $\begin{array}{c}\text { Reuse } \\
\text { Risk }\end{array}$ \\
\hline 101 & 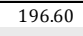 & $\begin{array}{l}638.00 \\
\end{array}$ & $\begin{array}{l}\text { Low } \\
\end{array}$ & 4.49 & 7.25 & 7.78 & 9.20 & 4.48 & 3.65 & $\begin{array}{l}1.17 \\
\end{array}$ \\
\hline 102 & 51.80 & 185.00 & Low & $4.4 c$ & 7.60 & 6.81 & 8. & 4.4 & 4.31 & 0.83 \\
\hline 103 & 64.10 & 332.00 & Low & 4.58 & 5.48 & 9.71 & 8.20 & 4.4 & 4.83 & 1.50 \\
\hline 104 & 131.00 & 619.90 & Moderate & 5.2 & 5.80 & 10.67 & 10.43 & 4.63 & 5.56 & 2.03 \\
\hline 105 & 13 & 64.80 & Moderate & 6.3 & & 16 & 16.0 & 6. & & 1.50 \\
\hline 106 & 19.90 & 76.60 & Low & 4.97 & 5.95 & 11.21 & 8.23 & 4.41 & 4.80 & 2.44 \\
\hline T01 & 3.00 & 1.20 & Low & 3.68 & 5.21 & 6.06 & 8. & 3.95 & 2.82 & 0.78 \\
\hline T02 & 2.00 & 2.00 & Lon & 4.0 & & 6.2 & s. & 5.4 & 2.9 & .54 \\
\hline T03 & 4.25 & 4.50 & Low & 4.16 & 5.32 & 6.34 & 10.34 & 5.5 & 2.97 & 0.54 \\
\hline T04 & 10 & & Lo & & & & 1. & 4 & 4.4 & 190 \\
\hline T05 & $15.0 \mathrm{c}$ & 4.00 & Low & 4.58 & 7.04 & 3.60 & 7.87 & 4.65 & 4.05 & 1.95 \\
\hline T06 & 40.53 & 22.00 & ow & 4.70 & 7.66 & 6.64 & 10.01 & 2.67 & 6.58 & 1.51 \\
\hline T07 & 4.05 & 2.0 & ow & 4.94 & 7. & 6.56 & 12.0 & 2.5 & .58 & 1.25 \\
\hline T08 & 31.85 & 5.00 & Low & 4.79 & 4.78 & 11.22 & 10.94 & 3.13 & 4.19 & 1.50 \\
\hline T09 & 114.28 & 18.00 & Moderate & 5.18 & 5.91 & 10.94 & 12.21 & 2.78 & 6.14 & 0.66 \\
\hline $\mathrm{T} 10$ & 23.1 & & oderat & & 1. & 10.75 & 12.6 & & 89 & \\
\hline T11 & 1.37 & & & 3.38 & 4. & 6.88 & 5. & 3.14 & 92 & .54 \\
\hline & & & & & & & & & & \\
\hline
\end{tabular}

TABLE VII. PROJECT RISK ASSESSMENT USING FUZZY-EXCOM (TURKISH- INDUSTRY DATA SET) 